\title{
Troponin I level in risk stratification of non-ST-elevation myocardial infarction in smokers
}

\author{
Iram Shahriar'1, Shahina Sobhan² and Ziarrat Islam³
}

Department of ${ }^{1}$ Pharmacology, ${ }^{2}$ Biochemistry and ${ }^{3}$ Cardiology, National Institute of Cardiovascular Diseases, Dhaka, Bangladesh.

\begin{tabular}{|c|c|}
\hline \multicolumn{2}{|l|}{ Article Info } \\
\hline Received: & 13 December 2010 \\
\hline Accepted: & 26 December 2010 \\
\hline Available Online: & 15 January 2011 \\
\hline \multicolumn{2}{|c|}{ DOI: 10.3329/bjp.v5i2.6666 } \\
\hline \multicolumn{2}{|c|}{$\begin{array}{l}\text { Cite this article: } \\
\text { Shahriar I, Sobhan S, Islam Z. Tro- } \\
\text { ponin I level in risk stratification of } \\
\text { non-ST-elevation myocardial infarc- } \\
\text { tion in smokers. Bangladesh J Phar- } \\
\text { macol. 2010; 5: 82-84. }\end{array}$} \\
\hline
\end{tabular}

\begin{abstract}
A prospective study was carried out to evaluate the role of troponin I in risk stratification of non-ST-elevation myocardial infarction in 40 smoker and 40 non-smoker patients. The troponin I was significantly higher $(\mathrm{p}<0.001)$ in smokers $(35.5 \pm 5.2 \mathrm{ng} / \mathrm{mL})$ than non-smoker $(0.3 \pm 0.0 \mathrm{ng} / \mathrm{mL})$. The duration of hospital stay was longer in Group I (106.6 \pm 2.4 hours) than in Group II (49.2 \pm 1.0 hours). The major adverse cardiac event was higher in smoker $(71.8 \%)$ compared to non-smokers $(10.8 \%)$. So, it may be concluded that higher value of troponin I with history of smoking in non-ST-elevation myocardial infarction may be considered as 'high-risk group' patients.
\end{abstract}

\section{Introduction}

Acute coronary syndrome includes unstable angina, non-ST-elevation myocardial infarction and STelevation myocardial infarction. Pathogenesis begins with atherosclerosis, characterized by endothelial thickening, lipid deposition, which is gradually converted to fibrous plaque formation (Gardner and McMillan, 1973). Most of the adverse cardiac events in non-ST-elevation myocardial injury arises from disruption of atheromatous plaque followed by platelet aggregation and thrombus formation that causes vascular occlusion (Main et al., 2004). Cigarette smoking is one of the most important risk factors for acute coronary syndrome. Smoking impacts all the phases of atherosclerosis (Mayhan and Sharpe, 1996). In Bangladesh over $50 \%$ male and 3\% female are cigarette smokers (Millat, 2005). Polycyclic aromatic hydrocarbons, nicotine and carbon monoxide in cigarette smoke decreases vasodilatory nitric oxide, increases local infiltration of leucocytes and lipid peroxidation that accelerates atherosclerosis (Black, 1995). Cardiac injury causes release of troponin I in peripheral circulation and serves as reliable marker of cardiac injury (Cummins et al., 1987). Cardiac troponin I rises by seven hours of onset of chest pain and remains elevated for several days (Adams et al., 1993).

A positive troponin I test in patients with unstable angina, myocardial infarction, non-ST-elevation myocardial infarction and heart failure is associated with high-risk of death and nonfatal myocardial infarction four times higher than in negative troponin I test (Antman et al., 1996).

The association of higher value of troponin I and increases progression of atherosclerosis process in smoker provides an opportunity to compare the risk of adverse cardiac events in smoker and non-smokers. The present study was carried out to evaluate the role of troponin I in risk stratification of non-ST-elevation myocardial infarction in smokers and non-smokers.

\section{Materials and Methods}

This prospective study was carried out 80 patient admitted in coronary care unit from January to July 2008. Inclusion criteria were patients with acute chest 
pain within 24 hours of chest pain and ECG showed non-ST-elevation myocardial infarction. Exclusion criteria were ST elevation on ECG history of myocardial infarction and heart failure and previous PTCA/CABG. Patients were further divided into two groups on basis of smoking habit (3-15 sticks/day of different brand), and no history of smoking habit.

Both groups received nitrates, heparin, aspirin, clopidogrel and calcium channel blocker as required. Data was collected by standard questionnaire that includes information of duration of chest pain, history of smoking, diagnosis, duration of hospital stay. Troponin I was measured by chemiluminescent immunometric assay (Immulite 100, Siemens, USA). Follow-up of patients were done by contact over telephone or in Outpatient Department to monitor for any adverse cardiac events in hospital and thirty day after discharge. All data analysis were done by SPSS software. Unpaired t-test was done to see any difference in two groups.

\section{Results}

Baseline characteristics of smoker and non-smoker patient are presented in Table I. Patient of both group were matched in respect to age, sex, duration of chest pain, previous CABG/PTCA. Significant difference was not observed between two groups. Troponin I level was

Table I

Baseline and admission characteristics

\begin{tabular}{|lcc|}
\hline End point & $\begin{array}{c}\text { Smoker } \\
(\mathrm{n}=39) \%\end{array}$ & $\begin{array}{c}\text { Non-smoker } \\
(\mathrm{n}=37) \%\end{array}$ \\
\hline Myocardial infarction & 61 & 8.1 \\
Revascularization & 7.6 & 2.7 \\
Death & 2.5 & 0 \\
Combined major cardiac event & 71.8 & 10.8 \\
\hline
\end{tabular}

Table II

\begin{tabular}{|lcc|}
\hline \multicolumn{3}{|c|}{$\begin{array}{c}\text { Shows the percentage of major adverse } \\
\text { cardiac events }\end{array}$} \\
\hline Variables & $\begin{array}{c}\text { Smoker } \\
(\mathrm{n}=40)\end{array}$ & $\begin{array}{c}\text { Non-smoker } \\
(\mathrm{n}=40)\end{array}$ \\
\hline Age (year) & 51.5 & 52.15 \\
Male & 22 & 23 \\
Female & 18 & 17 \\
Mean duration of chest & 7.9 & 8.8 \\
pain (hours) & & - \\
Previous myocardial in- & - & - \\
farction, CABG/PTCA & & - \\
ST- elevation on ECG (\%) & - & \\
\hline
\end{tabular}

significantly higher $(\mathrm{p}<0.001)$ in smokers $(35.5 \mathrm{ng} / \mathrm{mL})$ than in non-smoker $(0.3 \mathrm{ng} / \mathrm{mL})$. The mean hospital stay is longer in smokers (106.0 \pm 2.4 hours) compared to $(49.2 \pm 1.0$ hours $)(p<0.001)$. Table II shows the comparison of major cardiac events (MACE) in both groups. Smokers showed higher major cardiac events $(71.8 \%)$ compared to non-smokers $(10.8 \%)$. One patient from smoker group and two patients from non-smoker groups were lost from follow-up.

\section{Discussion}

Several studies have reported that cigarette smoking exposes individual to cardiovascular morbidity and mortality (Mayhan and Sharpe, 1996). Troponin I is considered as valuable biomarker to convey prognostic information for patient with non ST-elevation myocardial infarction. In the present study the value of troponin I was higher in smokers.

Clinical and experimental studies indicates that free radicals arising from cigarette smoke produces oxidative stress that decreases vasodilatory nitric oxide, increase lipid peroxidaion, adhesion of platelet to endothelium and ultimately thrombus formation (Adams, 1993). Longer duration of hospital stay was observed in patient with higher value of troponin I. This indicate that response to treatment in smoker is slower due to extensive myocardial damage than in non -smoker. Similar observation were found by Alp et al., 2001 and Hamm et al., 1997. The higher combined major cardiac adverse events in smoker compared to non-smoker correlates with higher value of troponin I in smokers that suggest remarkable myocardial injury that demands immediate and aggressive treatment. This result of the study is described elsewhere (Hamm, 1997; Sabatine et al., 2002).

\section{Conclusion}

This study suggests that patient with higher value of troponin I and history of smoking with non-STelevation myocardial infarction may be considered as 'high-risk group'.

\section{References}

Adams JE, Bodor GS, Davila-Roman VG, Delmez JA, Apple FS, Ladenson JH, Jaffe AS. Cardiac troponin I: A marker with high specificity for cardiac injury. Circulation 1993; 88: 10106.

Alp NJ, Bell JA, Shahi M. A rapid troponin I based protocol for assessing acute chest pain. QJM. 2001; 94: 687-94.

Antman EM, Tanasijevic MJ, Thompson B, Schactman M, McCabe CH, Cannon CP, Fischer GA, Fung AY, Thompson 
C, Wybenga D, Braunwald E. Cardiac-specific troponin I level to predict the risk of mortality in patient with acute coronary syndrome. N Engl J Med. 1996; 335: 1342-49.

Black HR. Smoking and cardiovascular disease. In: Hypertension: Pathophysiology, diagnosis and management. Largh JH, Brenner BM (eds). $2^{\text {nd }}$ edi. New York, Ravan Press Ltd., 1995, pp 2621-47.

Cummins B, Auckland ML, Cummins P. Cardiac-specific troponin I radioimmunoassay in the diagnosis of acute myocardial infarction. Am Heart J. 1987; 113: 1333-44.

Gardner C, McMillan MD. Development of arteriosclerosis. Am J Cardiol. 1973; 31: 542-46.

Hamm CW, Goldmann BU, Heeschen C, Kreymann G, Berger $\mathrm{J}$, Meinertz T. Emergency room triage of patient with acute chest pain by means of rapid testing for cardiac troponin $\mathrm{T}$ or troponin I. N Engl J Med. 1997; 337: 1648-53.
Main C, Palmer S, Griffin S, Jones L, Orton V, Sculpher M, Henderson R, Sudlow C, Hawkins N, Riemsma R. Clopidogrel used in combination with aspirin compared with aspirin alone in treatment of non-ST-segment-elevation acute coronary syndrome: A systematic review and economic evaluation. Health Technol Assess. 2004; 8: 1-141.

Mayhan WG, Sharpe GM. Effect of cigarette smoke extract on arteriolar dilatation in vivo. J Appl Physiol. 1996; 81: 19962003.

Millat MH. Smoking is hazardous to health. The Daily Star. January 2, 2005.

Sabatine MS, Morrow DA, de Lemos JA, Gibson CM, Murphy SA, Rifai N, McCabe C, Antman EM, Cannon CP, Braunwald E. Multimarker approach to risk stratification in non-ST elevation acute coronary syndrome: Simultaneous assessment of troponin I, C-reactive protein, B-type natriuretic peptide. Circulation 2002; 105: 1760-63. 